\title{
Não conformidades encontradas nas auditorias oficiais do SISBOV realizadas em Minas Gerais
}

\author{
Non-compliances found in the official audits of SISBOV held in Minas Gerais \\ Leonardo Gonçalves Teodoro Caixeta ${ }^{1}$, Marcos Aurélio Lopes ${ }^{1 *}$, Fábio Raphael Pascoti Bruhn
}

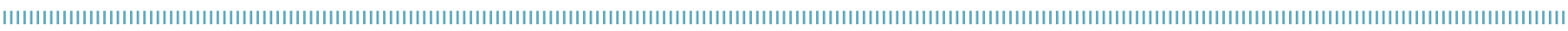

RESUMO: Objetivou-se realizar o levantamento das não conformidades encontradas durante as auditorias oficiais do Sistema Brasileiro de Identificação e Certificação de Origem Bovina e Bubalina (SISBOV) em Minas Gerais, entre 2009 e 2010. Na pesquisa qualitativa foram coletados dados referentes às principais não conformidades encontradas que levaram à suspensão ou cancelamento da certificação do estabelecimento rural aprovado no SISBOV (ERAS). Em 2009 foram realizadas 484 auditorias, sendo que 141 foram consideradas não aptas para inclusão na Lista Traces. Em 2010 foram realizadas 310 auditorias em ERAS, sendo que 55 tiveram resultado negativo. O conjunto de dados analisados foi obtido em uma amostra de 64 relatórios náo conformes no ano de 2009 e de 27 relatórios não conformes em 2010. Em 2009 foram constatadas 168 não conformidades, sendo que as principais foram: erro no preenchimento das Planilhas de Identificaçáo e no preenchimento dos Comunicados de Entrada e checagem do rebanho incorreta. Em 2010 foram encontradas 58 não conformidades, sendo que as principais foram: erro no preenchimento das Planilhas de Identificação, no preenchimento dos Comunicados de Entrada e no preenchimento dos Comunicados de Saída. Conclui-se que as principais não conformidades encontradas se devem ao preenchimento incorreto de documentos. Tais erros podem ser evitados, desde que certificadoras e produtores deem mais atençáo e maior importância ao preenchimento da documentaçáo.

PALAVRAS-CHAVE: bovinocultura; certificação; rastreabilidade; segurança alimentar.

\begin{abstract}
The objective of this research was survey the non-compliances found during the official audits of the Brazilian Beef and Buffalo Identification and certification System (SISBOV) in Minas Gerais, Brazil, between 2009 and 2010. In the qualitative research, data concerning the main non-compliances found in these reports were collected, which led to the suspension or cancellation of the SISBOV approved rural enterprise certification (ERAS). In 2009, 484 audits were conducted, 141 being considered unsuitable for being included in the in Traces list. In 2010, 310 ERAS audits were performed and 55 of them had a negative result. The data set analysed was obtained from a sample of 64 non-compliance reports in the year 2009 and 27 non-compliance reports in 2010. In 2009 there were found 168 non-compliances, the main ones being: mistakes in filling in the Identification Spreadsheets and the Entrance Reports; and incorrect herd checking. In 2010, 58 noncompliances were found, the main ones being: mistakes in filling in the Identification Spreadsheets, Entrance and Exit Reports. It is concluded that the main non-compliances found are due to the incorrect filling of documents. Such mistakes can be avoided, provided that certifying entities and breeders pay more attention and give more importance to filing documents.
\end{abstract}

KEYWORDS: cattle; certification; traceability; food safety.

\footnotetext{
'Departamento de Medicina Veterinária da Universidade Federal de Lavras (UFLA) - Lavras (MG), Brasil. *Autor correspondente: malopes@dmv.ufla.br 
A palavra rastreabilidade indica a capacidade para acompanhar o percurso de um produto ou de conhecer o seu processo de produçáo, manipulação, transformação, embalagem ou expediçấo. Rastreabilidade animal consiste no acompanhamento de todos os eventos ocorridos durante a vida de um animal, ou seja, é o registro de todas as ocorrências, manejos e movimentaçóes ocorridas desde seu nascimento ou identificação até o abate, momento esse que se estende até o consumo de suas partes.

O grave quadro da sanidade animal na Europa, no final do século XX, com o advento da encefalopatia espongiforme bovina (BSE, do inglês bovine spongiform encephalopathy) ou doença da vaca louca, das toxi-infecçóes alimentares e da contaminação de alimentos por resíduos químicos, gerou uma grande desconfiança por parte dos consumidores. Para reconquistar essa confiança e atender à demanda de consumidores, que a cada dia se tornam mais conscientes, a exigência da rastreabilidade das informaçôes referentes aos alimentos se torna uma condição cada vez mais importante (Cócaro; Jesus, 2007).

A exigência dos mercados importadores buscando cada vez mais produtos de qualidade, sem risco sanitário, provocou uma mudança de atitude no segmento industrial da carne bovina no Brasil. Para se adequar às normas impostas pelo cenário mundial, principalmente pela Uniāo Europeia (UE), o Ministério da Agricultura, Pecuária e Abastecimentos (MAPA) (BrasiL, 2002) criou o Sistema Brasileiro de Identificação e Certificação de Origem Bovina e Bubalina (SISBOV). Atualmente, vigora a Instrução Normativa no 65 (Brasil, 2009a), que instituiu o Sistema de Identificação e Certificação de Bovinos e Bubalinos, que visa estabelecer normas para a produção de carne bovina e bubalina com garantia de origem e qualidade, agregar valor à carne produzida e, consequentemente, obter melhores preços.

A rastreabilidade no Brasil ainda se destaca por uma diferenciação nos preços ao se atender à exigência da UE. Para os produtores brasileiros obterem essa bonificaçáo pela carne exportada, eles precisam aderir ao SISBOV e posteriormente ter sua propriedade incluída na lista Traces. Essa é a listagem dos estabelecimentos rurais aprovados no SISBOV (ERAS), habilitados à exportação de carne bovina e bubalina para a UE. Os ERAS são aprovados em auditorias oficiais e validados para exportação pela UE. De acordo com o MAPA, em 25/09/2014 o Brasil possuía 1.614 propriedades na lista Traces, sendo 295 em Minas Gerais, perfazendo $18,27 \%$ do total das propriedades brasileiras (BRASIL, 2014).

O ERAS será supervisionado por uma única certificadora, que fará o cadastramento da propriedade junto à Base Nacional de Dados (BND) e, obrigatoriamente, todos os bovinos e bubalinos serão identificados individualmente.
A partir da inclusão dos animais na $\mathrm{BND}$, cada bovino e bubalino terá um Documento de Identificação Animal (DIA), o qual o acompanhará durante toda a vida até sua baixa no sistema, seja por morte natural, abate ou sacrifício. Todas as movimentações dos animais deverão ser acompanhadas pelos respectivos DIAs (Cócaro; Jesus, 2007; Brasil, 2006).

Assim, uma propriedade rural que queira se tornar apta a exportar carne para a UE, além de aderir ao SISBOV e ser certificada por uma entidade certificadora, precisa passar por um processo de auditagem. A Auditoria Técnica Oficial propóe-se a avaliar o cumprimento dos requisitos, exigências, atribuiçôes e responsabilidades estabelecidas, determinar a conformidade ou não conformidade dos procedimentos técnicos de acordo com as normas operacionais do SISBOV. As auditorias oficiais são realizadas por fiscais federais agropecuários ou por servidores dos órgáos de defesa agropecuária dos estados e do Distrito Federal, com formação profissional de Médico Veterinário, Engenheiro Agrônomo ou Zootecnista, que detenham competência para o exercício da fiscalização agropecuária, desde que previamente habilitados para tal atribuição (BRASIL, 2006).

$\mathrm{Na}$ auditoria oficial faz-se a checagem do rebanho e a conferência documental. Nos ERAS com até 300 animais, a checagem e anotação dos códigos SISBOV será da totalidade do rebanho. Naqueles com até 600 animais serão anotados no mínimo 300 números, e no restante deverá ser observada a aplicabilidade dos elementos de identificação. Em caso de ERAS com mais de 600 animais, serão anotados no mínimo 300 números e conferidos outros 300 animais, totalizando no mínimo 600 animais. Será analisado, durante a auditoria, o livro de registro do ERAS presente na propriedade, contendo os documentos, termo de adesão à norma operacional do SISBOV, cadastro do estabelecimento rural, cadastro do produtor rural, inventário dos animais, protocolo declaratório de produção, controle de insumos utilizados — tais como produtos veterinários, suplementação alimentar e mineral, fertilizantes e corretivos agrícolas —, eventos sanitários, planilhas de identificaçâo, registro de movimentaçôes, entre outros (BRASIL, 2009b).

Qualquer descumprimento de requisitos especificados na normativa do SISBOV gera uma não conformidade (Brasil, 2006). O relatório de auditoria (check list), versão 07-2009, contempla náo conformidades menores e maiores. Se encontradas não conformidades menores, o ERAS possui 30 dias para correção e essa deverá ser apresentada na Superintendência Federal de Agricultura (SFA) do estado do ERAS. A falta de manifestaçáo no prazo determinado ou no caso das açóes corretivas náo serem suficientes, o ERAS perderá a certificação. Já a verificação 
de alguma náo conformidade maior gera a perda imediata da certificação do ERAS. Estando o produtor comunicado, a partir da assinatura do relatório com itens de não conformidade(s) maior(es), o retorno da certificação está condicionado à realização de vistoria conforme no estabelecimento, pela certificadora. Dessa forma, o ERAS receberá nova auditoria oficial, que será realizada de acordo com cronograma oficial de auditorias (BRASIL, 2009b).

Assim, objetivou-se realizar o levantamento das principais não conformidades encontradas durante as auditorias oficiais realizadas no estado de Minas Gerais, nos anos de 2009 e 2010. Espera-se que com tal levantamento seja possível sugerir propostas para sanar as não conformidades.

Esta pesquisa utilizou como base o modelo de relatório de auditoria V. 07-2009 informatizado, disponibilizado pela Coordenação de Sistemas de Rastreabilidade do MAPA e utilizado nas auditorias em todo país.

Fez-se o levantamento das auditorias oficiais realizadas no estado de Minas Gerais nos anos de 2009 e 2010 pelos auditores do Instituto Mineiro de Agropecuária (IMA), órgáo de defesa agropecuária do estado de Minas Gerais. $\mathrm{Na}$ pesquisa qualitativa foram coletados dados referentes às principais não conformidades maiores e menores encontradas nesses relatórios que levaram à suspensão ou cancelamento da certificação do ERAS e, consequentemente, à não inclusão na lista Traces.

Em 2009 foram realizadas 484 auditorias, sendo que 141 foram consideradas não aptas para inclusão na Lista Traces. Já em 2010 foram realizadas 310 auditorias em ERAS, sendo que 55 tiveram resultado negativo. O conjunto de dados analisado foi obtido em uma amostra de 64 relatórios náo conformes no ano de 2009 e de 27 relatórios não conformes em 2010.

Os dados foram analisados por meio de estatísticas descritivas simples e agrupados em tabelas, objetivando uma melhor apresentação, comparaçáo e discussão dos resultados (Lopes, 2004).

No ano de 2009, em 64 auditorias realizadas, foram encontradas 168 não conformidades, uma média de 2,62 $( \pm 1,75)$ por auditoria. Dessas, 156 foram não conformidades maiores e 12 menores, com médias de 2,43 $( \pm 1,62)$ e $0,18( \pm 0,43)$, respectivamente. Em 2010, em 27 auditorias, foram relatadas 58 náo conformidades, com média de 2,14 ( $\pm 1,26)$, sendo 52 maiores e 6 menores, com médias de $1,92( \pm 1,41)$ e $0,22( \pm 0,50)$, respectivamente. $\mathrm{O}$ fato da quantidade de náo conformidades maiores encontradas ser excessivamente superior à quantidade de não conformidades menores é explicado pela quantidade de itens que gera uma náo conformidade maior ser superior aos itens que levam a uma não conformidade menor, 26 versus 6 .
Houve uma reduçáo da quantidade de auditorias não conformes entre os anos de 2009 e 2010, de 141 para 55 , portanto, uma queda de $61 \%$. Consequentemente, a quantidade de não conformidades também diminuiu de 168 para 58, uma queda de 65,5\%. Observa-se que o percentual de redução de não conformidade foi superior ao de vistoria não conforme ( 65,5 versus $61 \%)$. Tal fato pode evidenciar a melhora por parte dos pecuaristas em compreender e implementar o SISBOV, ressaltando um processo de profissionalização da atividade pecuária, da melhoria dos serviços prestados pelas certificadoras e maior qualidade das empresas que permanecem na área de certificação. Lopes (2007a) demonstrou que $25 \%$ dos produtores entrevistados apontaram a falta de compreensão das normas do SISBOV como principal dificuldade na implantação do sistema. Já $45 \%$ indicaram que as mudanças frequentes das normas seriam a principal dificuldade. Esse fato se torna ainda mais relevante uma vez que Lopes (2007b) mostrou que, ao serem entrevistadas 24 certificadoras credenciadas, em 50\% delas as mudanças das normas do SISBOV seriam a principal dificuldade encontrada para o rastreamento de bovinos. Com o passar do tempo, verificou-se um aperfeiçoamento nas regras do SISBOV, se adequando cada vez mais ao típico sistema de criação de bovinos do país, evolução por parte das certificadoras e dos produtores em assimilar e pôr em prática as normas vigentes.

Com relação às não conformidades maiores, no ano de 2009 (Tabela 1) encontrou-se, em 39 relatórios de auditoria $(60,93 \%$ dos pesquisados), erro no preenchimento das Planilhas de Identificação; em 20 relatórios $(31,25 \%)$, erro no preenchimento dos Comunicados de Entrada; em 18 relatórios $(28,12 \%)$, a checagem do rebanho estava incorreta, significando que a quantidade de animais encontrada na propriedade estava diferente da quantidade presente na BND. Para a propriedade ser considerada apta para a UE não se aceita diferença no quantitativo de animais; em 11 $(17,18 \%)$ auditorias pesquisadas foram constatados animais sem os dois elementos de identificação; portanto, esses não estavam rastreados. No ano de 2010 , os resultados mais importantes foram: em 16 relatórios de auditoria $(59,25 \%)$, erro no preenchimento das Planilhas de Identificação; em 6 relatórios $(22,22 \%)$ foi constatado que havia animais sem os dois elementos de identificação; portanto, esses não estavam rastreados. Nesse mesmo ano não foi relatada náo conformidade no item de checagem do rebanho nos check lists pesquisados. Tal fato evidencia um maior controle dos nascimentos, das entradas, saídas e mortes dos animais, por parte dos produtores.

Realizando-se a análise dos dois anos, percebe-se que as não conformidades mais frequentes são relacionadas ao preenchimento incorreto de documentos por parte do 
pecuarista. Uma possível explicação para o fato seria uma falta de habilidade ou zelo em trabalhar com documentos, ou a falta de revisão desses por parte das empresas certificadoras. Ultimamente, observa-se que tais documentos estão sendo feitos de forma informatizada; essa seria uma medida plausível para evitar erros e rasuras na produçấo desses documentos. É comum, nas auditorias, se deparar com uma grande perda dos elementos de identificação, principalmente brinco auricular e bottom. Essa ocorrência pode sugerir que os elementos de identificação não estấo sendo aplicados da maneira correta, ou não estâo resistindo às ocorrências normais do dia-a-dia, tais como temperatura, brigas entre os animais, cercas, galhos, entre outros. Seria interessante que os produtores utilizassem outros métodos de identificação, como marca a fogo, tatuagem ou dispositivos eletrônicos (chip intrarrumenal, chip subcutâneo ou chip instalado na cicatriz umbilical.
As frequências das principais não conformidades menores relatadas nas auditorias em 2009 e 2010 estão apresentadas na Tabela 2. Não foi encontrado na literatura estudo semelhante que pudesse proporcionar resultados para que fossem comparados com os encontrados nesta pesquisa.

Conclui-se que houve uma diminuição na quantidade de auditoras não conformes no ano de 2010 em relação a 2009, demonstrando uma evolução por parte dos pecuaristas e certificadoras em assimilar e implantar as regras do SISBOV. Porém, ainda há uma quantidade expressiva de não conformidades no que se refere ao preenchimento de documentos. Pelo fato das náo conformidades descredenciarem as propriedades para a exportaçấo de carne para a UE, as certificadoras deveriam dar maior ênfase a esse ponto, repassar as informaçôes necessárias e cobrar dos produtores o correto preenchimento de toda a documentação.

Tabela 1. Principais não conformidades maiores encontradas em 91 auditorias oficiais no estado de Minas Gerias em 2009 e 2010.

\begin{tabular}{|c|c|c|}
\hline Não conformidades maiores & $\begin{array}{l}\text { Frequência } \\
\text { (\%) em } 2009\end{array}$ & $\begin{array}{l}\text { Frequência } \\
\text { (\%) em } 2010\end{array}$ \\
\hline Nome do produtor & 3,12 & 7,40 \\
\hline Protocolo Declaratório de Produção & 10,93 & 7,40 \\
\hline Inventários & 10,93 & 0,00 \\
\hline Planilhas de Identificação dos Animais & 60,93 & 59,25 \\
\hline Preenchimento de Comunicados de Entrada & 31,25 & 33,33 \\
\hline Comunicados de Entrada com recebido do Órgão Executor de Sanidade Animal & 1,56 & 3,70 \\
\hline Preenchimento de Comunicados de Saída & 25,00 & 29,62 \\
\hline Comunicados de Saída com recebido do Órgão Executor de Sanidade Animal & 6,25 & 3,70 \\
\hline Preenchimento de Comunicados de Morte & 14,06 & 11,11 \\
\hline Todas as GTA's estão presentes no ERAS & 6,25 & 0,00 \\
\hline Checagem do rebanho & 28,12 & 0,00 \\
\hline Presença dos elementos de identificação nos animais observados & 17,18 & 22,22 \\
\hline Estoque de brincos confere com o número de elementos pedidos e não aplicados & 4,68 & 0,00 \\
\hline $\begin{array}{l}\text { Conferência de identificação (checar se os números de identificação estão no } \\
\text { extrato de animais vivos do ERAS) }\end{array}$ & 17,18 & 11,11 \\
\hline Checar se os números de identificação anotados no estoque não foram incluídos na BND & 1,56 & 3,70 \\
\hline
\end{tabular}

GTA: Guia de Trânsito Animal; ERAS: estabelecimento rural aprovado no Sistema Brasileiro de Identificação e Certificação de Origem Bovina e Bubalina; BND: Base Nacional de Dados.

Tabela 2. Principais não conformidades menores encontradas em 91 auditorias oficiais no estado de Minas Gerias em 2009 e 2010.

\begin{tabular}{lrr} 
Não conformidades menores & $\begin{array}{c}\text { Frequência } \\
(\%) \text { em 2009 }\end{array}$ & $\begin{array}{c}\text { Frequência } \\
(\%) \text { em 2010 }\end{array}$ \\
\hline Nome do ERAS & 1,56 & 3,70 \\
\hline Nome do proprietário & 1,56 & 11,11 \\
\hline Tipo de estabelecimento (essa opção está de acordo com a registrada na BND) & 7,81 & 0,00 \\
\hline Comunicados de Morte com recebido do Órgão Executor de Sanidade Animal & 6,25 & 7,40 \\
\hline O certificado do ERAS está dentro do prazo de validade & 6,25 & 0,00
\end{tabular}

ERAS: estabelecimento rural aprovado no Sistema Brasileiro de Identificação e Certificação de Origem Bovina e Bubalina; BND: Base Nacional de Dados. 


\section{REFERÊNCIAS}

CÓCARO, H.; JESUS J.C.S. Impactos da implantação da rastreabilidade bovina em empresas rurais informatizadas: estudos de caso. Journal of Infomation Systems and Technology Management, v.4, n.3, p.353-374, 2007.

BRASIL. Ministério da Agricultura, Pecuária e Abastecimento. Instrução Normativa no 1 , de 9 de janeiro de 2002. Diário Oficial da União, Brasília, 10 de janeiro de 2002. Seção 1, p.6.

BRASIL. Ministério da Agricultura, Pecuária e Abastecimento. Instrução normativa no 17 , de 13 de julho de 2006. Diário Oficial da União, Brasília, 14 de julho de 2006. Seção 1, p.23-37.

BRASIL Ministério da Agricultura, Pecuária e Abastecimento. Instrução Normativa $n^{\circ}$ 65, de 16 de dezembro de 2009. Diário Oficial da União, Brasília, 17 de dezembro de 2009a. Seção 1, p.19-20.

BRASIL. Ministério da Agricultura, Pecuáriae Abastecimento. Disponível em: http://www.agricultura.gov.br/animal/noticias/2012/02/ ministerio-divulga-fazendas-aptas-a-exportar-para-a-ue, jan. 2014.
BRASIL. Ministério da Agricultura, Pecuária e Abastecimento. Instrutivo para preenchimento do novo relatório de auditoria do Sisbov em ERAS. 30 jul. 2009b. Disponível em: http://sisbov.agricultura.gov.br/sisbov_new/principal_sisbov, dez. 2010.

LOPES, M.A.; LIMA, A.L.R.; CARVALHO, F.M.; REIS, R.P.; SANTOS, I.C.; SARAIVA, F.H. Controle gerencial e estudo da rentabilidade de sistemas de produção de leite na região de Lavras (MG). Ciência e Agrotecnologia, v.28, n.4, p.883-892, 2004.

LOPES, M.A.; SANTIOS, G.; AMADO, G.B.; CARDOSO, M.G. Principais dificuldades encontradas pelos pecuaristas na implantação da rastreabilidade de bovinos. Ciência Animal Brasileira, v.8, n.3, p.515-520, 2007a.

LOPES, M.A.; SANTOS, G. Principais dificuldades encontradas pelas certificadoras para rastrear bovinos. Ciência e Agrotecnologia, v.31, n.5, p.1552-1557, 2007b. 